\title{
Modernidad y posmodernidad en El gran señor de Enrique Rosas Paravicino
}

Modernidade e pós-modernidade em El gran Señor, de Enrique Rosas Paravicino

\section{Miguel Arribasplata Cabanillas}

Universidad Nacional de Educación Enrique Guzmán y Valle - La Cantuta - Cajamarca - Peru

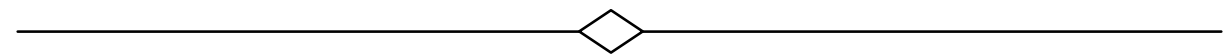

Resumen: En la novela El Gran Señor de Enrique Rosas Paravicino hay una confluencia de pasado histórico y presente conflictivo, donde el fervor religioso cumple un papel de nucleo integrador. En la sociedad andina ficcionalizada aparece una novedosa galería de tipos sociales, como corresponde a un país, como Perú, en pugna por integrar la modernidad con la tradición cultural. Los Andes se constituyen en el gran escenario de una épica popular, con todo el colorido de sus gentes y el paisaje de su cultura. Todo se mueve en torno a un rasgo que es predominante en la novela: el desplazamiento humano en torno a una devoción en plena Cordillera Oriental: el Cristo de la Nieve Resplandeciente. Aquí el sincretismo religioso da lugar a la presencia de personajes involucrados en el mito, la magia y la tradición oral, a la par que asoman los cambios sociales y políticos impulsados por otros actores embarcados en proyectos mundanos, acordes con ese otro gran mito: el progreso colectivo, en perspectiva al desarrollo nacional.

Palabras-clave: El gran señor. Tradición cultural. Modernidad y posmodernidad. Narrativa andina peruana.

Resumo: Em El Gran Señor, de Enrique Rosas Paravicino, há uma confluência de passado histórico e presente conflituoso em que o fervor religioso cumpre o papel de um núcleo integrador. Na sociedade andina ficcionaliada, aparece uma galeria inovadora de tipos sociais, como corresponde a um país, como o Peru, em luta para integrar a modernidade com a tradição cultural. Os Andes constituem um grande cenário de uma épica popular, com todo o colorido de gentes e a paisagem de sua cultura. Tudo se move em torno a um traço que é predominante no romance: o Cristo da "Nieve Resplandeciente". Aqui, o sincretismo religioso dá lugar à presença de personagens envolvidos no mito, na magia e na tradição oral, ao mesmo tempo em que assomam as mudanças sociais e políticas impulsionadas por atores embarcados em projetos mundanos, de acordo com outro grande mito: o avanço coletivo, na perspectiva do desenvolvimento nacional.

Palavras-chave: El gran señor. Tradição cultural. Modernidade/Pós-Modernidade. Narrativa andina peruana. 
La lectura de narraciones con temática neoindigenista, que reproduce con nuevos apartados formales las condiciones de explotación y las relaciones sociales y de poder, donde el acto del agravio, el deseo de la venganza y los mitos sin retorno cancelan la visión de una sociedad y de una cultura que, más allá del antropologismo, han sido invadidas por el capitalismo de alta intensidad, es un esquema que nos ofrece más de lo mismo, y que como lector me ha alejado de la percepción de una literatura que no tenga los implantes o herencias del indigenismo. ¿Escribir de otro modo, narrar desde otra perspectiva es alejarse del sabor de la tierra? Concebir la creación de mundos posibles, en los que la imaginación recree lo que hay del humus del pueblo, de la comunidad, del espíritu y de la cultura sembrada y florecida en el Ande, ¿es abandonar la gran tradición literaria de José María Arguedas y Ciro Alegría? La alta dosis de lirismo, la exhaustiva descripción, que garantizan, entre otros factores, al indigenismo ¿puede ser reemplazada por un lenguaje más "sereno" y eficaz? ¿Modernidad y posmodernidad pueden manifestarse a la par en una obra?

Enrique Rosas Paravicino asume el reto de confrontar estas y otras interrogantes, sin salirse del canon de la literatura con universos andinos. No es un escritor que está perturbado por el Ello, pero sí por la condición humana. Lo suyo no es un discurso de la hegemonía. Tampoco es un mero discurso signado para el consumo local.

El Gran Señor tal vez sea la primera novela anclada en el Ande cusqueño que concentra su temática en el fervor religioso, en el encuentro con el ritual, el mito, la fe religiosa, el paganismo, el sincretismo, elementos que permanecen inmutables a los influjos repentinos del otro mito -el de la supuesta revolución- bastardeado por el puro afán de la venganza, pero puesto en marcha con una cerrada convicción. En la referida novela, el presente y el pasado se manifiestan y coinciden para enjuiciar, repetir, ratificar los avatares de la historia. El culto es el mismo de siglos atrás, la fe permanece, no se subordina a la jerarquía oficial, es consustancial al pueblo, el colectivo andino es su pasado y su presente. En esa memoria radica su fortaleza y su continuidad.

Es que el culto es ejercido y reinterpretado con una representatividad social emergida de las canteras populares. En el apogeo del culto aparece una nueva tipología de sujetos: Lizandro Jordán, reciente rico, minero, otrora de condición humilde, que desde las vetas de oro del río Inambari, retorna al Cusco para ostentar su riqueza durante la veneración al Señor de la Cordillera.

José María Arguedas, en Todas las sangres nos presenta a un nuevo personaje protagónico en la tipología de la novela indigenista: El cholo Cisneros, un mestizo, quien a fuerza de abuso y prepotencia asciende a la condición de nuevo y tosco gamonal. El mestizo ya no es el papeluchero o tinterillo, ni el adulón o agente, mucho menos mayoral, de los señorones o hacendados, sino el franco competidor de estos últimos, en el afán de acumular más tierras y poder.

Enrique Rosas transita de la modernidad a la posmodernidad, no solo en la representatividad de las ceremonias religiosas sino que, haciendo una lectura de las nuevas relaciones sociales gestadas en el mundo que representa, acierta diseñando un personaje fruto de la penetración capitalista en el campo y de la migración interna, que también se refleja en la misma capital de la república, en los espacios del comercio y la industria. Son mestizos los de la nueva casta de ricos, quienes no reniegan de sus costumbres y orígenes, pero que sí constituyen el otro poder, el paralelo a la oligarquía tradicional. Lizandro Jordán es aceptado en la élite religiosa como mecenas de la Iglesia y del santuario cordillerano. Él no es protagonista de ninguna épica de los pobres, ni tampoco perece en la acción; se afirma socialmente, hace alarde de su nuevo estatus, agradece a su divino benefactor.

Una trama cobra atracción estética cuando se condensa en la variedad y riqueza del dominio virtual, en especial en el campo de los fueros privados, en la individualización y tipología de los personajes. Rosas Paravicino ha trazado su estrategia narrativa no en el dominio privado, al percibir que la existencia ficcional 
es un asunto intencional. En un astuto juego de dados apuesta por subvertir los cimientos de la literatura de corte neoindigenista, sin resentir el contexto, dejando de lado -a nivel técnico o formal- la manera de narrar y de representar el mundo posible o ficcional del modo modernista, para pasar a la posmodernidad, con el énfasis cultural como protagonista ideológico. Y más aún: no hay un personaje guía y ordenador, ni un "héroe problemático", a la manera de la novela tradicional o decimonónica -indigenista o neoindigenista-, todos actúan en función a la voluntad del colectivo en movimiento.

En El Gran Señor se percibe una nueva manera de producir significados, sin recurrir a golpes de suerte vanguardistas o giros arbitrarios. Un pueblo entero, una abigarrada multitud heterogénea es la protagonista que gira en torno a la fe y la adoración al Cristo de la Rinconada. Multitud viva bullente y multitud muerta, también bullente. Frontera natural y sobrenatural coexisten hasta lograr un mundo híbrido, unificado. Vivos y difuntos asisten a las misas con mucha emoción, con reverencia sagrada, que les permite -a los vivos- rechazar la intromisión senderista en el santuario, por constituir la acción de los rebeldes un acto profanatorio y atentatorio.

Asimismo, lo visible y lo invisible concurren a este ceremonial henchido de truenos, rayos, cóndores y miríadas de pájaros, así como del enjuiciamiento y castigo a Mateo Pumacahua, personaje controvertido que en la sublevación de 1780 prefirió servir a los españoles. La historia no deja cabos sueltos cuando la ficción se ocupa de ella. El gran Túpac Amaru refulge tácitamente en esta novela, como el gestor y conductor de esta sublevación anticolonial.

En un libro tan sugerente como polémico, titulado El sueño de los justos, Juan Carlos Ubilluz y otros autores acuden al concepto lacaniano de fantasma para explicar cómo lo que ellos llaman "El fantasma de la nación cercada" afecta por igual a novelas de referencia criolla o citadina, así como a novelas andinas o de referencia rural. En el tema del fantasma, la primera parte del libro se detiene para dejarnos en claro que las conclusiones del Informe de Uchuraccay calan en el discurso literario de Mario
Vargas Llosa, Alonso Cueto, Santiago Roncagliolo, Oscar Colchado y Felix Huamán Cabrera, en sus obras Lituma en los Andes, La hora azul, Abril rojo, Rosa Cuchillo y Candela quema luceros respectivamente. Y ciertamente cada uno de ellos, lo único que hacen es luchar con una imagen preconcebida, que nada tiene que ver con el problema medular del conflicto de la década de los 80s. La pregunta es: si la modernidad afecta, o no, al mundo andino y qué mecanismos emplear para asimilarlo. Lo que crea el fantasma contra el que se lucha es más bien una forma sesgada y maniquea de abordar el hecho real, favoreciendo a toda clase de elucubraciones justificadoras del conflicto, algo así como que el mundo del Ande no conoció ni conoce la modernidad, que las muertes en el conflicto interno son consecuencia de un pensamiento mítico, mesiánico o simplemente religioso, o que finalmente hablamos de mundos tan distintos en los que la comunicación es imposible. El meollo del asunto en el planteamiento de Ubilluz es desestabilizar la creencia de la nación cercada, impulsada por el cuadro antropológico planteado por el Informe de Uchuraccay, por lo que más bien opta por una lectura problemática del asunto, abordando incluso la elogiada película Madeinusa y hallando en ella la misma visión fantasmática, con la presencia de cierto paternalismo versus el salvajismo del hombre andino.

De ahí que lo que queremos desarrollar en este trabajo es la idea de si la novela de Rosas Paravicino, El gran señor, es una pieza narrativa en la que el fantasma de la nación cercada opera también como un señuelo o una pantalla que subyace en ella, o quizá ya no. Para empezar, tomemos el siguiente extracto de un trabajo de Juan Carlos Galdo:

En la novela El gran Señor (1994) es, sin embargo, donde la relación entre presente y pasado se desarrolla con mayor riqueza y mayor complejidad. La novela tiene por escenario la festividad de Qoyllurrit'i, masivo y populoso culto andino cusqueño; originalmente de arraigo exclusivamente campesino, que tiene lugar en las Provincias Altas del departamento del Cusco. Significativamente el milagro: la aparición de un Cristo niño en una rinconada al pie de un nevado) ocurre en 1780. La instauración oficial de este culto coincide con la Revolución 
tupacamarista en una zona que apoyó en forma masiva al líder indígena poniendo en evidencia como lo histórico y lo cultural, lo profano y lo sagrado, en palabras de Rosas, se entrelazan, y se explican uno en función del otro. ¿Qué ocurre entonces en el presente cuando columnas senderistas no solo disputan el control de la zona sino que terminan infiltrándose en la festividad misma? Los peregrinos los confrontan abiertamente, es más, quieren lincharlos una vez que son descubiertos. La indignación que resiente desborda el carácter profanatorio para manifestar un modo de concebir el mundo. Al reaccionar de esta manera están rechazando también una interferencia inaceptable al interior de un culto, que, por sobre sus estructuras jerárquicas e instancias disciplinarias, se expresa en términos de una organización popular por completo ajena al fanatismo secular que se les pretende imponer. (GALDO, 2000, p.97)

Si asumimos lo que la novela desarrolla como materia narrativa, nos daremos cuenta que casi toda la historia se desenvuelve en un lugar sagrado, en un ámbito religioso, donde año tras año se efectúa la adoración al Señor de Qollurit'i. Un grupo de subversivos pertenecientes a una columna de Sendero Luminoso se infiltra en ese evento. El objetivo de esta columna es aniquilar a sus enemigos, aprovechando la cobertura de sus disfraces de pabluchas (personajes que representan a un grupo de adoradores que cargan el anda del Señor de la Cordillera). El disfraz los favorece tanto así como las explosiones de las bombardas para no dejar rastros de la balacera y las bombas que han de usar. Pero, muy a pesar de las simulaciones del grupo, los fieles que participan de esa festividad, al darse cuenta de la presencia del grupo subversivo, capturan a sus miembros y los entregan a las autoridades.

Esta historia que, creemos, es lo central en la novela, ocurre en un tiempo actual, digamos en la contemporaneidad. Hay otras historias acerca de pugnas ancestrales como las luchas por las tierras de épocas ya pereclitadas, entre hacendados y campesinos. Además está el caso de Mateo Pumacahua, quien como un fantasma angustiado expía sus culpas en los glaciares del Vilcanota. De esta manera, Rosas Paravicino hace una serie de propuestas sobre la historia, sobre todo plantea que la violencia en las relaciones humanas, por lo menos en el ámbito que sirve como referente en la obra, no es de ahora; tiene una larga historicidad. Las motivaciones de los desencuentros de antaño pudieron ser otros, pero la violencia en los Andes se ha dado de manera permanente.

Para poder establecer algunas ideas sobre argumentos más o menos válidos, tomemos en cuenta una entrevista que le hicieron a Rosas Paravicino, acerca de su obra en cuestión:

"En su novela El gran señor los subversivos
se infiltran en el santuario, entre la gente con
fervor religioso, incluso asesinan ahí. Se
profana lo sagrado. ¿Los subversivos son
herejes desde esta perspectiva? ¿Se ha visto
situaciones parecidas en la realidad?"
(ARÉVALO, 1994

Ante esta pregunta, el escritor andino expresa algunas ideas que nos servirán para sustentar nuestro comentario.

"Responderé a esta pregunta con un caso
real. En mi calidad de peregrino de la
festividad de Qoyllurit'i del Cusco, vi una vez
que dos jóvenes danzaban indistintamente en
las comparsas de bailarines de Ocongate y
Paucartambo. Ambos eran alumnos míos en
la Universidad Nacional San Antonio Abad del
Cusco. Los conocía desde hacía varios
semestres como radicales activistas de la
izquierda legal. Sin embargo, más adelante
me enteré que ambos terminaron enrolándose
en las filas de Sendero Luminoso. Aquí
participarían en atentados sangrientos, con
secuelas trágicas hasta la vez que la policía
desbarató al comando sedicioso y capturó a
sus componentes. Una tarde, los presentó a
todos en conferencia de prensa y allí estaban
los dos danzantes del santuario. Más que
simples herejes, ambos habían derivado en
militantes de un proyecto político que
anunciaba barrer el sistema para, sobre sus
escombros, construir otro tipo de sociedad.
Este caso nos demuestra que, en los Andes,
no hay mayor divorcio entre la práctica
religiosa popular y la opción política violenta".
(ARÉVALO, 1994)

Lo que argumenta el novelista en esta respuesta extractada, es que hay una evidente secuencia en la historicidad de las prácticas culturales en los Andes peruanos. Reitero, hay historicidad pero no anclaje en la premodernidad ni solo en la modernidad. En nuestra apreciación, aunque un poco forzada, hay homología entre danzantes y subversivos, por cuanto la novela escenifica una evolución, un cambio no sólo de personajes sino del 
mismo evento mayor que sirve para relacionar a unas prácticas culturales anteriores en el tiempo con otras nuevas. En este punto (si tomamos en cuenta lo que dice Galdo en el sentido de que la novela puede también incorporar las resonancias de la rebelión tupacamarista), es claro que la novela de Rosas se distingue de las propuestas culturales que implícitamente exponen, por ejemplo, Candela Quema luceros de Huamán Cabrera o Rosa Cuchillo de Colchado, novelas en las cuales la historia no se desliza, se mueve sobre su mismo eje; el pasado no transita hacia el presente, más bien como que se desliza hacia atrás. Como podemos visualizar, la novela de Rosas no se sirve del pasado para negar el presente sino para hacernos observar que las relaciones humanas en el Ande han transitado de la premodernidad a la modernidad, incluso a la posmodernidad, porque el accionar de los grupos subversivos se puede asumir como una evidencia de que los grandes relatos 0 , por lo menos, los símbolos de los grandes relatos se han caído de su pedestal; ya no merecen la adoración de antaño. Aquí se podría argumentar que si bien es cierto que el gran relato cristiano ha caído, éste ha sido reemplazado con el metarrelato del marxismo.

Por otro lado, en la novela de Rosas Paravicino, no se vislumbra la influencia del fantasma de la nación cercada. Este fantasma establece que el Perú está escindido en dos mundos: uno andino y otro criollo, citadino o costeño, con una incapacidad total y completa de interrelación. Se trataría de dos mundos que no hallan vínculos de encuentro. Este esquema cultural esgrimido reiteradas veces por Vargas Llosa, incluso por Arguedas, es asumido casi con escándalo por los supuestos escritores andinos como Colchado y Huamán Cabrera y otros seguidores de la línea ficcional de Arguedas. Como se podrá apreciar, también sin el mayor esfuerzo, salvo el esfuerzo de conocer con pertinencia la categoría psicoanalítica de fantasía, en la novela de Rosas Paravicino no opera el esquemacitado. Por el contrario, la historia está definida por el tiempo y no solo por el espacio y los sucesos en el mundo de las relaciones humanas andinas. En este sentido, la lectura de Galdo es insuficiente, limitada, acerca de la novela en cuestión. La mirada de Galdo está anclada también en el estereotipo de que el mundo andino es otro mundo con respecto al resto del Perú. Si bien es cierto que en esa mirada hay atisbos de reconocimiento en el sentido de que la novela El gran señor transita de la premodernidad a la modernidad, incluso a la posmodernidad, hay otras expresiones que borran con el codo lo escrito con la mano de la razón crítica culturalista.

Volviendo a la primera parte, es decir, a la disyuntiva de si El gran señor es una novela anclada en el fantasma de la nación cercada, y de si es aún una propuesta de un mundo y de una concepción del mundo premoderno en cuanto a la cosmovisión de sus personajes, llegamos a la conclusión que esta novela no cae en los tentáculos invisibles de la fantasía cultural denominada 'fantasma de la nación cercada'. Simplemente porque transita de la premodernidad cultural a la modernidad e, incluso, a la posmodernidad en la secuencialización de los elementos referenciales que le sirven de contenido. En consecuencia, podemos afirmar que El gran señor es una novela que se distancia tanto de las novelas criollas como andinas ancladas aún en los parámetros de la fantasía de la nación cercada.

El lenguaje en esta novela resplandece sereno para comunicar todo un retablo de vidas multicolores, de diálogos y polifonías de un pueblo vigoroso y activo, que se ha juntado ante la convocatoria del culto, o la fe en el Señor de la Cordillera, mezclada con celebraciones y encuentros de identidades heterogéneas.

Sencillo, cuando conviene, pero además eficaz, el lenguaje se corporiza: laf laf, sopla el viento en la altura. Laf, laf cruzan el cielo unos patos viajeros, lenguaje que asume su papel condensador de toda una circunstancia. Rosas Paravicino doma al quechua en su encuentro con el español, sin chamuscar la palabra, sin indicios de lucha entre uno y otro idioma ni subordinaciones subalternas; tampoco apela a diminutivos serviles, aciagos recursos seudoefectistas de ciertos narradores andinos. Lenguaje no afectado ni ceremonioso, 
trabajado con el cincel de la metáfora, del artesano que esculpe la lengua sin perturbarla con el estilo académico, y con mucho matiz connotativo, libre del formalismo quisquilloso; en suma, lenguaje que se enseñorea en este culto que sintetiza lo que hay de fe: Todas las provincias estaban aquí reunidas, y todo el aire del mundo contenido en esas dos flautas que hacían vibrar el templo (133).

La cordillera provoca sensaciones y misterios en ese punto de encuentro de tanto creyente en el Señor. La vida siempre es trajín para el hombre y mucho más qué afanado es el mundo cuando anda uncido a la fe. La adoración y la fe son el leit motiv de la novela. La multitud está abigarrada en torno al santuario, el sincretismo pagano cristiano convive a flor de encuentros y celebraciones, religión y vida festiva se socializan de modo tal que esto es un envite para la fe y la alegría. Mural de gentes con su peregrinación ruidosa y ceremonial alrededor del Taytacha de Qoyllurit'i y del zapateo de bailarines que parecía copiarse de una jineteada (133). La danza, por fin en una novela peruana no es el mero acontecer emocional sino el leit motiv esencial en el contexto de la reliogiosidad popular y su tributación o pago.

Transando con el bullicio, la gente se entiende de todos modos en esta fiesta que hervía como la chicha en una vasija (133). Novela de danza explosiva y sagrada, a voluntad y sudor de alturas siderales. En resumen, Rosas Paravicino ajusta su lenguaje a todo el mosaico de voces. Este es el otro mérito, tan igual en el desafío del narrador cusqueño, no solo en la novela abordada, sino también en sus demás textos, tanto de género narrativo como en el ensayo.

\section{Referências}

ANDREU, Alicia, El testimonio peruano oral y las Ciencias Sociales. Lima / Berkeley: Latinoamericana editores, 2000.

ARÉVALO, Javier, "La religiosidad popular novelada. Entrevista con Enrique Rosas". Lima, Diario "El Comercio", 12 de julio de 1994.
ARGUEDAS, José María: Los ríos profundos. Buenos Aires, Ed. Losada, 1958.

BARTHES Roland, El grado cero de la escritura. Buenos Aires, Ed. Jorge Álvarez, 1957.

BOBES, NAVES, María del Carmen, La novela. Madrid, Ed. Síntesis, 1998.

COLCHADO, Lucio, Rosa Cuchillo. Lima. Ed. San Marcos, 1997.

CORNEJO POLAR, Antonio, Los universos narrativos de José María Arguedas. Buenos Aires, Ed. Losada, 1973.

FUENTES, Carlos, Geografía de la novela. México, Fondo de Cultura Económica, 1993.

GALDO, Juan Carlos, "Algunos aspectos de la narrativa regional contemporánea: los casos de Enrique Rosas Paravicino y Oscar Colchado Lucio". Lima, Revista Lexis, Vol. XXIV, № 1, 2000.

HUAMAN CABRERA, Félix: Candela Quema luceros. Lima, Ed. San Marcos, 1997.

KUNDERA, Milan, El arte de la novela, Madrid, Ed. Tusquets, 1994.

OVIEDO, José Miguel, Mario Vargas Llosa: la invención de una realidad. Barcelona, Ed. Anagrama, 1970.

ROSAS PARAVICINO, Enrique, El Gran Señor. Lima, Ed. San Marcos, 2000.

VARGAS LLOSA, La utopía arcaica. José María Arguedas y las ficciones del Indigenismo. Lima, Fondo de Cultura Económica, 1996.

ZEVALLOS A. Ulises Juan, Indigenismo y nación. Los retos a la representación de la subalternidad aymara y quechua en el Boletín Titicaca. Lima, IFEA, 2002. 